\title{
1 Editor's introduction: we never know the worth of water till the well is dry ${ }^{1}$ Kevin Cullinane
}

There can be no doubt that the discipline of maritime economics has undergone rapid and dramatic development in recent years. This is in part a reflection of the ongoing dynamics of the maritime industry itself, as manifest in the pivotal changes that have occurred with respect to:

- the globalization of manufacturing and the changes in trade patterns this has induced;

- the increasingly dominant role within the sector played by containerized transport;

- the greater industrial concentration and wider geographical coverage of both shipping companies and port operations;

- the deployment of larger containerships and associated adoption of hub-and-spoke operations;

- the worldwide proliferation of devolved port governance systems with greater private sector participation;

- the increasing importance attached to safety, security and the environment; and

- the continuing shift in the maritime nexus towards Asia and away from Europe.

Of particular relevance are those dynamics that have prompted the emergence of new perspectives on the sector; initially as an important element of international logistics, and more latterly as an integral component in, and contributor to, global supply chains. This realignment of perspective has led, inter alia, to the emergence of new thinking on the nature of both the hinterland and network concepts as applied to the maritime context and to the joint and separate impact of each on the competitiveness of maritime entities.

This altered landscape is mirrored by equally significant changes in what today constitutes the maritime economics community. As reflected in the membership of the International Association of Maritime Economists, not only has this community grown in recent years, but there has also been a transition in the nature of the individuals comprising that community. 


\section{International handbook of maritime economics}

As just one example in support of this view, the interface of maritime economics with the wider transport community is now much stronger than it ever has been. No doubt, this is as a direct result of the emergence of the logistics perspective in freight transport, the increasing relevance of short sea shipping - particularly as an element within intermodal transport solutions - and the very real prospect of the maritime mode playing a significant role in greenhouse gas reduction. Mainstream research methods and techniques from land-based transport studies have increasingly been absorbed and utilized within maritime economics and many approaches that have long been recognized in maritime economics circles - particularly in the area of finance - are readily applied in research which is focused on the wider transport context. Indeed, many individual researchers that in the past were exclusively associated with either maritime or land-based transport now have a (research-active) foot in both camps, and the representation of maritime-related research in the transport journals has proliferated. A similar overlapping of interests has occurred between maritime economics and the operations management field, with many operations research/operations management (OR/OM) techniques and approaches emerging as central to many areas of maritime economics research. It is the hope and intention that the content of this book represents this great research diversity in all its infinite variety.

The discipline of maritime economics has its own widely accepted areas of specialization. At the broadest level, and focusing on the most significant categories of specialization, a significant proportion of research in traditional maritime economics can be described as any of bulk shipping economics, liner (container) shipping economics or port economics. Chapters 2-4 of this book deal with issues, however, that can be considered as rather generic to the maritime field and, hence, cannot be very easily pigeonholed into any one of these specializations. As such, the topics addressed in these first few chapters can, in many respects, be considered to be cross-cutting in nature. In structuring the remainder of the book, however, an attempt is made to cluster chapters together into their relevant specialized field within the maritime economics arena. This is not to say, however, that there are not close linkages between chapters that cut across these somewhat artificial boundaries.

It is appropriate that this book should begin with a macroscopic perspective on the worldwide maritime arena. The annual Review of Maritime Transport, published by the United Nations Conference on Trade and Development (UNCTAD), has covered the port and shipping businesses

for more than 40 years, providing data and analysis on international seaborne trade, the world fleet, ports and global freight markets. As a complement to what has become its widely cited Review of Maritime 
Transport, UNCTAD initiated its quarterly Transport Newsletter in 2004. In Chapter 2 of this book, Hassiba Benamara, Jan Hoffmann and Vincent Valentine, from UNCTAD's Trade Logistics Branch, present an overview of the key developments affecting the maritime industry over the last few decades. Supplemented by more recent statistical updates and structuring their analysis around the three cornerstones of the maritime economics discipline - demand, supply and markets - the authors draw upon these comprehensive and definitive sources in order to identify and focus on major long-term developments within the maritime sector.

We then move to a topic that has been of some significant concern to both UNCTAD and the maritime economics community over the years. In tonnage terms, the majority of the world's shipping fleet has for some time been registered with so-called 'flags of convenience'. Panama, Liberia and the Bahamas have been long-term market leaders in attracting this 'offshore' registration of ships, but new market entrants such as the Marshall Islands, Malta and Cyprus are now also making inroads into this potentially lucrative market. Despite the ongoing contentious arguments over their very existence, it comes as hardly any surprise that this proliferation in the use of 'flags of convenience' is anticipated to continue and expand into the future.

In recognition of the strategic significance of the ship registration decision, the objective of Chapter 3, by Manolis Kavussanos and Andrianos Tsekrekos, is to provide a theoretical framework which helps explain the interaction of factors that influence the decision to register with a 'flag of convenience', highlighting the risk-return trade-off that is at its core. In pursuing this objective, the authors formulate the decision problem as a switching option under the assumptions of uncertainty and costly reversibility. Their findings show that uncertainties over the level of savings in tax and labour costs that accrue from 'flagging-out', as well as the level of correlation of a vessel's operation with the market portfolio, can together influence the likelihood and timing of registry switching decisions. They conclude that the optimal flag-switching policy for a maritime firm can be influenced by a number of factors, and that their model offers a feasible mechanism for assessing the available fleet registration alternatives.

From as long ago as the 1920s, a great deal of activity in maritime economics has been concerned with the measuring, cataloguing and modelling of prices (freight rates) in shipping markets, particularly in the bulk shipping sector. Today, available market data comes largely in the form of specialized indices and averages of freight rate series that are derived from the details contained in actual completed contracts in the market. Where no such transactions exist within a given period, the data series is often made complete on the basis of brokers' estimates. In Chapter 4, Albert Veenstra 
and Jan van Dalen highlight the variation which exists in the manner that these freight rate indices are determined and the way price index series are calculated and reported as part of official (government or supranational) statistics. The authors address this potential gap by taking into account the duration of time charters in the determination of formal freight rate indices that are calculated from fixtures data. Their analysis reveals that duration-based indices have a much smoother development than transaction-based time-charter indices. They also find that indices based only on fixtures contain much less information than either duration-based indices, or industry data that include brokers' estimates. They conclude that this provides clear evidence that brokers' estimates do add structure and information to pure fixture data and that this raises a question over the extent to which data from brokers' estimates have determined the outcomes of some of the modelling work produced since the 1980s.

Chapter 5 by Photis Panayides and Neophytos Lambertides relates to the efficiency analysis of firms operating in the tanker and dry bulk shipping markets. Ostensibly, the work would appear to fall within the category of mainstream bulk shipping economics. However, the authors' chosen approach is to estimate the efficient frontier for dry bulk and tanker firms and to evaluate the level of deviation from this frontier as a proxy for relative efficiency. For the estimation of the efficiency frontier, the authors apply data envelopment analysis (DEA) - a methodology that has been widely applied in the maritime economics literature for estimating the efficiency of ports or terminals. Thus, the relationship to port economics is obvious. This unusual application of the methodology to bulk shipping companies involves the use of net income, the book value of equity, leverage, profitability and asset turnover in order to examine the relative operational efficiency of firms. The conclusions of this work suggest that tanker firms are more market-efficient than dry bulk firms which, in turn, are found to be more operationally efficient than tanker firms, with the latter indicating possible market mispricing in the dry bulk shipping industry.

In Chapter 6, David Glen presents the results of his attempts to model the behaviour of oil spill numbers published by the International Tanker Owners Pollution Federation (ITOPF) over the period 1997-2005. His analysis involves the estimation of Poisson count or negative binomial models to identify the major determinants of oil spill numbers over this period. The results are used to estimate the numbers of oil spills that would have occurred in the absence of the adoption of double hull technology. The author concludes that other potential factors, such as changes in the regulatory regimes regarding oil transportation, are found to exert an insignificant influence over the variable of interest. 
Turning to another prevalent form of risk in shipping, in Chapter 7, Amir Alizadeh and Nikos Nomikos consider the risks associated with shipping investment and operations and how these can be managed. They highlight the magnitude of the risks associated with investing in shipping but, at the same time, assert that while risks are high, so too are the potential returns. Risk management in shipping has traditionally been viewed as an activity which undermines profit-making potential. However, as is evident in the growth of traded volumes of freight derivatives, recent increases in the level of freight rates, coupled with the exceptionally high degree of volatility in the bulk markets in particular, have changed the way that investors in shipping markets view, and deal with, risk and uncertainty. Utilizing a data set of ship prices and spot- and time-charter earnings, the authors analyse the return, risk and utility performance of two different investment strategies in the tanker and dry bulk shipping sectors. The results indicate that a freight-rate risk management strategy can improve the overall risk-return profile of shipping investment projects and that, interestingly, hedging strategies prove to be more effective for investment in larger vessels in both the sectors analysed.

The content of the book now moves to the broad arena of liner, or container, shipping economics with Mike Fusillo's analysis, in Chapter 8, of the potential for this sector to become increasingly concentrated now that liner shipping conferences have virtually disappeared from US markets and have been eliminated from European trades. He hypothesizes that the larger, more cost-efficient carriers may drive smaller players from the market and, ergo, the significant risk exists that shippers will be faced with fewer alternatives for moving their goods, lower service quality and significantly higher prices. The author explores the neoclassical motivations for mergers and examines a series of liner shipping mergers and acquisitions (M\&A) activity within the context of industry structure and regulatory constraints. In relation to US liner shipping markets, he formulates and then estimates a Poisson model aimed at extracting and quantifying the structural factors that increase the likelihood of horizontal M\&A activity. Outcomes from this modelling exercise provide some support for the neoclassical theory that industry-specific shocks motivate M\&A activity in liner shipping, particularly when demand conditions are unfavourable or when shocks to demand are positive, although the implementation of the Ocean Shipping Reform Act of 1998 (OSRA) is proposed as a confounding factor in the latter result. As predicted by neoclassical theory, regulatory reforms are found to prompt M\&A activity, and given the high fixed to variable costs ratio that characterizes the sector and the tendency towards the deployment of larger vessels that need to be filled, concentration in US liner shipping markets is bound to accelerate as one impact of 
Europe's removal of the exemption granted to liner shipping conferences from competition law.

With similar concerns over market concentration, in Chapter 9, Ricardo Sanchez and Gordon Wilmsmeier investigate the different theoretical approaches to measuring market concentration and the potential effects of market power on the evolution of liner shipping networks. The authors suggest that recent developments in the maritime industry, particularly the tendency towards greater concentration brought about by M\&A activity, are changing the structure of specific markets. In particular, smaller markets are increasingly under threat from collusive behaviour and oligopolistic market structures that may well leave shippers paying premium prices for international transport; a market characteristic that has critical implications for the economic development of countries and regions. By applying pivotal concepts from industrial organization, such as economies of scale, density and scope, as well as contestable market theory, the authors present evidence on market development and concentration for different trades in South America. They conclude not only that it is important to measure market concentration at the level of a specific trade, but also that concentration may be more prevalent than traditional measures might suggest. Most poignantly, the results of their analysis reveal that there is already a lack of contestability in South American maritime markets and that this may be stemming economic development within the region.

In attempting to facilitate worldwide trade, particularly as it impacts on less developed nations, another major concern in recent years has been the increasing costs of maritime transport resulting from the imposition of enhanced security measures following the events of $9 / 11$ and other terrorist atrocities. In July 2007, for example, the US Congress passed the Implementing Recommendations of the 9/11 Commission Act that requires the scanning of 100 per cent of US-bound containers at their last foreign port-of-call by the year 2012. In Chapter 10, Wayne Talley develops analytical models of maritime transport chains for US-bound containers, with the intention of investigating the likely impact of this legislation. The fundamental issue addressed is whether the implementation of the Act will alter the status quo of maritime transport chains utilized by shipping lines and shippers in the transportation of US-bound containerized cargo. For example, will they switch from direct-service to transhipment maritime transport chains? The author concludes that if scanning economies of scale exist, the legislation will have a positive impact (in terms of increased container throughput of US-bound containers) on foreign transhipment container ports that are the last ports-of-call for US-bound containers.

Another more long-standing, and certainly more contentious, source of 
cost inflation in container shipping has been the infamous bunker adjustment factor (BAF), a specific surcharge levied by liner shipping companies on their customers with the intention of passing on unexpected fuel price rises. Shipping lines have long argued that BAFs provide only partial compensation for short-term increases in their fuel costs, while shippers have always criticized the lack of transparency in their calculation and consistently assert that BAFs actually constitute an alternative form of revenue generation.

The magnitude of fuel price increases since 2004 has meant that BAFs now constitute quite a significant component of the overall cost of shipping goods. In addition, the ending of the conference era in Europe has prompted changes to the way in which individual container shipping companies approach the imposition and calculation of BAFs. These circumstances provide the fundamental motivation for the analysis contained in Chapter 11, by Theo Notteboom and Pierre Cariou. They seek answers to how shipping lines have changed their practices with respect to BAF following the demise of liner shipping conferences in Europe; how bunker costs and BAFs are estimated for specific services; and whether the BAF constitutes an instrument for either cost compensation or revenue generation. Utilizing extensive market data on fuel consumption, transit times, port time, vessel sizes and so on, the authors present a model that estimates the bunker cost for a specific service, taking into account specific vessel and service characteristics. They apply the model to a set of 117 port-to-port liner services originating in the port of Antwerp and compare model estimates of fuel costs with observed BAFs. Among other things, the authors conclude that the relationship between BAFs and freight rates is rather weak and that, very importantly, BAFs do indeed appear to involve a moderate to high element of revenue generation, but that this does not seem to be related to instances of low freight rates.

In Chapter 12, Arne Jensen and Rickard Bergqvist address an extremely fundamental aspect of liner shipping services which, again, impacts directly upon the cost of transporting intercontinental container flows: namely the decision on which ports to service with direct calls by large vessels and which ports to service by feeder vessels from (which) transhipment ports. A strategic support model for analysing the economic consequences of the alternative options for container service design is developed and its use illustrated with an empirical case study of intercontinental container flows moving to and from the port of Gothenburg in Sweden. The authors test a range of hypothetical scenarios which vary in terms of container volumes and number of operators involved in the shipping service. They deduce that, given sufficient volumes, a direct call system would be more cost-efficient than feeder-based services, particularly when 
maximum economies of scale can be reaped by a monopoly provider in a contestable market. They conclude that more direct services and the associated lower prices of transport for intercontinental containers will increase the competitiveness of the port of Gothenburg as a transhipment hub for container flows to and from the Baltic States and Russia, leading in turn to further port-based economies of scale. In addition, this system also has positive economic consequences for the city of Gothenburg and for Sweden in general. With a direct service system in place, they also conclude that there is greater scope for horizontal cooperation between shippers, both in Scandinavia and in its export markets, such that lower prices and higher quality of service can be secured with international carriers.

Chapter 13 represents a departure from the consideration of international container shipping, with Lourdes Trujillo, Francesca Medda and María González adopting a focus on the transport of freight over short to medium distances in their analysis of short sea shipping (SSS). In certain geographical contexts, notably within Europe, the prospect of utilizing a less environmentally damaging mode of transport that is not subject to the vagaries of a congested road system is an attractive proposition. For this reason, the promotion of SSS, with the intention of achieving a modal switch of freight, has been a pivotal element of EU transport policy for some time. As the authors of this chapter point out, however, SSS not only represents a competitor for road transport or conventional rail services on specific origin-destination pairs, but can also be regarded as a complement to other modes within intermodal movements. Its performance with respect to the latter is critically dependent on its integration within the overall transport system.

Taking account of the potential role of SSS, both as a substitute and a complement, this chapter analyses the advantages and disadvantages of SSS when compared with road transport and, based upon a review of the existing empirical evidence, outlines a formal approach to establishing the determinants that explain the intermodal effects of SSS. As the basis for undertaking an empirical intermodal analysis, a theoretical model is then developed which accounts for type of mode, as well as type of operator offering the service. Policy recommendations are deduced from the outcomes of the model and include the need simultaneously to remove barriers to the use of SSS and to incentivize modal switching from road to sea.

Irrespective of whether the focus of concern is on long-distance intercontinental maritime transport or more regionally-based, short- to mediumdistance shipping, the part played by ports in expediting maritime freight movements is a critical one and justifies its own specialism in the form of port economics. From a wider logistics perspective, however, container ports specifically can be regarded as storage points (that is, warehouses) 
to and from which both laden and empty containers move in and out, and inside of which containers may be processed, stored and/or have value added to. While the movement of laden containers to and from ports is ultimately driven by consumer demand, the movement of empty containers to and from container ports (that is, their repositioning) is controlled by liner shipping companies. In Chapter 14, Dong-Ping Song and Qing Zhang present an analysis which stands at the interface of the port and container shipping arena. They assert that due to trade imbalances and demand fluctuations, the inventory control of empty containers in ports is an important managerial issue for liner shipping companies and that the stochastic factors in the system and the time delay in container repositioning make the problem very challenging. The authors' objective is to find the optimal policy for empty container management in a port with random customer demand and time delays in repositioning. In seeking to achieve this objective, the authors propose a mathematical formulation of the problem and derive the optimal policy using discrete-time dynamic programming. Based on the observed structural characteristics of the optimal policy, a suboptimal threshold policy is proposed and the steady-state performance of the system under the threshold policy is analysed through the derivation of the stationary distribution. A full factorial experiment is then designed and implemented to compare the performance of the optimal policy, the threshold policy and an heuristic policy under a wide range of scenarios. The sensitivity of the threshold policy to its control parameters is also addressed.

Within the specific arena of port economics, the issue of competition between ports (particularly container ports) has received a great deal of attention. Numerous models have been developed and tested which attempt to capture, explain and predict port choice decisions, with the logit model formulation proving the most popular option among these. Chapter 15, by Simme Veldman and Eric van Drunen, has the objective of determining the existence of market power amongst container ports. Various techniques exist to assess this, most of which utilize the price elasticity of demand for a port as a prerequisite. This can be determined by estimating a logit model based on revealed or stated preferences. Thus, the authors formulate their own logit model of port choice, they then address estimation issues and, finally, the derivation of port choice elasticity is undertaken. The validity of the estimates they obtain and their applicability to the context of the market power of ports is assessed by comparing and contrasting their results with estimated price elasticities of demand as measured in seven port choice studies published since 2003.

The nature of a port's hinterland exerts a significant influence on the competitiveness of a port and ultimately, therefore, over the emergent 
outcome of any port competition that might exist. Most port operators and authorities have a very strong, almost intuitive, understanding of their hinterland, especially in relation to which parts of that hinterland are captive and which parts remain contestable. This understanding can, however, be difficult to communicate or to re-evaluate in the light of any changes which might occur. Chapter 16 by Jacob Kronbak and Kevin Cullinane presents the results of a research project where a geographical information system (GIS)-based model for the illustration and assessment of captive and contestable port hinterlands has been developed. The model can be used to visualize the cost structure which applies within port hinterlands as thematic maps; a tool which can provide useful and accessible information that facilitates the strategic planning performed by port management and administrations. The model consists of two basic constituent parts: a transport system submodel and a visualization tool. The former accounts for the costs associated with the ocean carriage, the port and, in terms of generalized cost, moving cargoes to and from the hinterland. The model also takes other direct costs into account, such as tolls or road pricing. Based on the modelling of the cost structure, a number of existing and new indicators are used to describe the captive and contestable port hinterland. On the basis of the contents of the transport system submodel, the visualization tool can then not only generate maps of the current situation, but also uses a number of different spatial analyses to illustrate the captive and contestable hinterland. The outcomes of tests of the model are presented, based on empirical data for the five container ports of Hamburg, Bremerhaven, Rotterdam, Antwerp and Le Havre. The authors conclude that the model and associated empirical application are capable of providing useful additional insights for port planning and decision-making, but that there is scope for including additional layers in the model not only for other physical modal networks (including feeder services), but also to cater for other more abstract hinterland characteristics.

Another vibrant area of port economics research which has received significant attention in recent years is that of port and/or terminal efficiency. This again, of course, relates directly to the issue of port competition and competitiveness; but also, on the basis of changes in port efficiency over time, it relates to the issue of port governance. In Chapter 17, Carlos Barros, Hercules Haralambides, Mohamed Hussain and Nicolas Peypoch analyse the efficiency and productivity growth of a representative sample of Middle Eastern and West African seaports from 2005 to 2007. They apply two alternative approaches in data envelopment analysis (DEA) to measure productivity growth: first, the Luenberger productivity indicator; and second, the Malmquist index. The two models generate a productivity indicator that is decomposed into the usual constituents of productivity 
growth: technological change and efficiency change. The results show that, on average, seaports in the sample regions did not experience productivity growth during the period analysed and that, indeed, with only a few notable exceptions, they have demonstrated a worrying decline in technical efficiency, often despite positive developments in the adoption of new technology. The authors conclude that their analysis points to the need for port reform and improved education and training in port and maritime management. As a broader policy implication and in support of exportled development strategies, they call for governments in the two regions to prioritize port development and financing.

The theme of port efficiency is continued in Chapter 18 by Angela Bergantino and Enrico Musso. In addition to managerial capacity, they seek to provide an estimation of the impact of exogenous factors, cleared of statistical noise, on the efficiency of ports. Exogenous factors that are explicitly considered include governance regime and local socio-economic conditions. Their analysis involves the application of a three-stage DEA procedure to a panel of European ports, observed over a ten-year period, which allows the decomposition of DEA efficiency measures into three components: exogenous effects, managerial inefficiency and stochastic events.

As a second stage in their analysis, they apply a stochastic framework model in order to identify the determinants of input-specific efficiency differentials across ports. The outcome shows that, in general, governancerelated factors and other external elements predominate over managerial skills in determining the efficiency conditions of ports. The third and final step of the analysis is to re-run the DEA calculations with the adjusted factors to determine efficiency scores cleared of exogenous influences. The authors assert that this procedure helps in gaining further insights into the evolution of the port industry in the EU and in proposing strategies for improving the operational performance of ports. They conclude that, in fact, there are significant variations in efficiency levels across the ports in the sample and that performances change significantly by controlling for factors considered outside the direct control of port managers.

The influence of port inefficiency on the costs of maritime transport and the damaging impact this has upon trade is emphasized in the imaginatively titled Chapter 19, where Paul Kent and Alan Fox exemplify the issue with their comparative analysis of the inefficient Puerto Limon in Costa Rica and the efficient port of Cartagena in Colombia. The authors attempt to discern the underlying causes of disaggregated disparities in cost efficiency and to arrive at an aggregate cost of inefficiency which they then treat as a tax in the Global Trade Analysis Project (GTAP) model to derive the impact that port inefficiency has on trade and welfare. The authors 
conclude that Central America's high freight rates cannot be attributable, as sometimes claimed, solely to low cargo volumes; port inefficiencies also exert a significant influence in terms of additional fuel costs and even, through overly long loading and discharging times, the number of ships which carriers deploy. All these avoidable additional direct costs, as well as the indirect additional inventory costs for shippers, serve to undermine Costa Rica's terms of trade and, ultimately, have a deleterious effect upon the nation's trade, economy and consumer welfare. The authors go on to propose that port reform that induces competition, particularly port privatization, is the best way forward for Central American nations such as Costa Rica whose economies are suffering as a consequence of an inefficient port sector. At the same time, the difficulties in doing so, particularly the strength of the labour unions, are acknowledged.

The last few chapters have focused on relatively mainstream perspectives on port efficiency. In contrast, the final chapter of this book, by Su-Han Woo and Stephen Pettit, puts a novel twist on the topic by adopting a more holistic approach to port efficiency - from the perspective of the wider supply chain within which ports operate. Ports are increasingly adopting different strategies in relation to the level and form of their integration into supply chains, in addition to the service quality and valueadded activities they provide. Perhaps in contrast to traditional measures, contemporary indicators of port efficiency are expected to be inclusive of all aspects of operations and to be consistent with the strategies of the organization. To this end, the authors investigate the changes currently taking place in the port industry and seek to develop a port performance framework which reflects these changes. Based on an exploratory study, they design and present a framework for doing so and confirm the validity and reliability of the framework by confirmatory factor analysis (CFA). The authors' analysis suggests that port performance is indeed multifaceted; that it is not limited merely to internal processes, but is also concerned with external service characteristics such as service quality and logistical aspects such as value-added service. The authors conclude that port operating companies and port authorities should strive to maintain a balanced focus on both effectiveness and efficiency aspects of performance management and improvement, aiming to meet the goals of customers and other parties within wider supply chains.

\section{Note}

1. A quotation from Thomas Fuller (1732), Gnomologia. 